\title{
Patients receiving chiropractic care in a neurorehabilitation hospital: a descriptive study
}

This article was published in the following Dove Press journal: Journal of Multidisciplinary Healthcare

\author{
Robert D Vining' \\ Stacie A Salsbury' \\ W Carl Cooley ${ }^{2}$ \\ Donna Gosselin ${ }^{3}$ \\ Lance Corber' \\ Christine M Goertz' \\ 'Palmer Center for Chiropractic \\ Research, Palmer College of \\ Chiropractic, Davenport, IA, USA; \\ ${ }^{2}$ Department of Pediatrics, Geisel \\ School of Medicine at Dartmouth, \\ Hanover, NH, USA; ${ }^{3}$ Independent \\ Consultant, Milford, NH, USA
}

Correspondence: Robert D Vining Palmer Center for Chiropractic Research, Palmer College of Chiropractic, 74I Brady Street, Davenport, IA 52803, USA

Tel + I 5638845690

Fax +I 5638845238

Email robert.vining@palmer.edu
Objectives: Individuals rehabilitating from complex neurological injury require a multidisciplinary approach, which typically does not include chiropractic care. This study describes inpatients receiving multidisciplinary rehabilitation including chiropractic care for brain injury, spinal cord injury (SCI), stroke, and other complex neurological conditions.

Design: Chiropractic services were integrated into Crotched Mountain Specialty Hospital (CMSH) through this project. Patient characteristics and chiropractic care data were collected to describe those receiving care and the interventions during the first 15 months when chiropractic services were available.

Setting: $\mathrm{CMSH}$, a 62-bed subacute multidisciplinary rehabilitation, skilled nursing facility located in Greenfield, New Hampshire, USA.

Results: Patient mean (SD) age ( $\mathrm{n}=27)$ was 42.8 (13) years, ranging from 20 to 64 years. Males $(\mathrm{n}=18,67 \%)$ and those of white race/ethnicity $(\mathrm{n}=23,85 \%)$ comprised the majority. Brain injury $(n=20)$ was the most common admitting condition caused by trauma $(n=9)$, hemorrhage $(n=7)$, infarction $(n=2)$, and general anoxia $(n=2)$. Three patients were admitted for cervical SCI, 1 for ankylosing spondylitis, 1 for traumatic polyarthropathy, and 2 for respiratory failure with encephalopathy. Other common comorbid diagnoses potentially complicating the treatment and recovery process included myospasm $(n=13)$, depression $(n=11)$, anxiety $(n=10)$, dysphagia $(n=8)$, substance abuse $(n=8)$, and candidiasis $(n=7)$. Chiropractic procedures employed, by visit $(n=641)$, included manual myofascial therapies (93\%), mechanical percussion (83\%), manual muscle stretching $(75 \%)$, and thrust manipulation (65\%) to address patients with spinal-related pain $(n=15,54 \%)$, joint or regional stiffness $(n=14,50 \%)$, and extremity pain $(n=13,46 \%)$. Care often required adapting to participant limitations or conditions. Such adaptations not commonly encountered in outpatient settings where chiropractic care is usually delivered included the need for lift assistance, wheelchair dependence, contractures, impaired speech, quadriplegia/ paraplegia, and the presence of feeding tubes and urinary catheters.

Conclusion: Patients suffered significant functional limitations and comorbidity resulting in modifications to the typical delivery of chiropractic care. Chiropractic services focused on relieving musculoskeletal pain and stiffness.

Keywords: chiropractic, spinal cord injury, stroke, rehabilitation, integrative medicine

\section{Introduction}

Persons suffering spinal cord injury (SCI), brain injury, or stroke with complicated sequela typically require multidisciplinary rehabilitation due to complex multisystem effects. ${ }^{1-3}$ Over 3,000 cases of acute SCIs occur within the USA each year ${ }^{4}$ as do an estimated 795,000 cerebrovascular accidents (stroke). ${ }^{5}$ Of the estimated 2.5 
million annual emergency department visits for traumatic brain injury (TBI), the US Centers for Disease Control and Prevention estimates $\sim 280,000$ persons are hospitalized for moderate to severe injury. ${ }^{6}$ Healthcare costs to manage moderate to severe TBI are more than US\$13 billion annually. ${ }^{7}$ Individuals recovering from acquired brain injury and SCI often experience limitations in physical mobility and activities of daily living, impaired cognition, psychological conditions, and chronic pain, which can lead to permanent institutionalization. ${ }^{5,7,8}$ Many patients with such complex neurological conditions are admitted to postacute rehabilitation settings or skilled nursing facilities to support their recovery process. ${ }^{5}$

Many factors can impede rehabilitation from complex neurological conditions including the presence of comorbidities such as pain, depression, cardiopulmonary disease, gastrointestinal disorders, substance abuse disorder, and musculoskeletal symptoms. ${ }^{9-11}$ Hemiplegic shoulder pain, a common poststroke disorder, is caused by several possible underlying pathologies that can significantly interfere with movement and sleep and contribute to delayed functional recovery. ${ }^{12}$ Individuals with SCI commonly experience spasticity, poor posture, and upper extremity overuse, which contribute to persistent musculoskeletal pain. ${ }^{13,14}$ Common conditions associated with brain injury include co-injury from polytrauma, headache from multiple etiologies, and cognitive changes that complicate both clinical assessment and treatment response. ${ }^{15,16}$

Rehabilitation-focused disciplines, such as physical, occupational, and speech therapies, support inpatients recovering from and adapting to complex neurological injury. Chiropractic services may also offer a positive contribution. Spinal manipulation, a therapy commonly used by doctors of chiropractic (DCs), is known to influence pain through complex central nervous system mechanisms. ${ }^{17}$ Evidence suggests other manual therapies commonly used by DCs also generate complex neurological response cascades leading to clinical improvement. ${ }^{18}$ Some of these interventions show promise for reducing pain in patients recovering from SCI. ${ }^{19}$ Because chiropractic services are integrated increasingly into outpatient multidisciplinary environments where nonpharmacological interventions are needed or preferred, ${ }^{20-24}$ exploring care that can be delivered in inpatient settings is a next logical step. ${ }^{25}$

Currently, little is known about chiropractic service delivery within the inpatient neurorehabilitation context. However, such knowledge is vital to informing integration decisions. Barriers to more widespread integration include a lack of utilization and cost data for the specific environment, ${ }^{26}$ perceived loss of autonomy for the chiropractic provider, ${ }^{27,28}$ and unfamiliarity with how chiropractic procedures can complement other treatments. ${ }^{29-31}$ The purpose of this study was to describe the clinical characteristics, chiropractic service utilization patterns, and common care challenges among patients with complex neurological conditions receiving subacute inpatient care including chiropractic at a rehabilitation specialty hospital.

\section{Materials and methods}

This descriptive study prospectively documented and retrospectively evaluated chiropractic care provided to adult rehabilitation inpatients during 15 months of a chiropractic integration project. Ethics approvals were obtained from the Palmer College of Chiropractic and Crotched Mountain Foundation Institutional Review Boards. Study participants provided written informed consent $(n=21)$ or assent with written consent from a legally authorized representative $(n=6)$ for all electronic health record releases.

\section{Setting and participants}

Crotched Mountain Specialty Hospital (CMSH) in Greenfield, New Hampshire, USA, is a 62-bed skilled nursing facility focusing on the rehabilitation needs of adult and pediatric patients suffering from brain injury, SCI, stroke, and other complex health conditions. CMSH employed a multidisciplinary staff that used an interdisciplinary model wherein care planning occurred through coordinated team-based processes. ${ }^{32,33}$ Patient and family priorities also influenced the treatment approach. Health disciplines at CMSH included internal medicine, pediatrics, physical therapy, physiatry, speech therapy, occupational therapy, therapeutic recreation, assistive technology, nursing, psychiatry, case management and psychology. Study participants included adults, age 18 years or older, and who were receiving inpatient rehabilitation and chiropractic services.

\section{Study design considerations}

Given the small patient census at the hospital and the considerable variation between patients with SCI and brain injury, answering the question of how chiropractic care, or the care of any other individual discipline, contributed to patient improvement was not scientifically feasible. The authors considered a case-control design, but the research-related risks (privacy and confidentiality concerns) outweighed any benefits for nonchiropractic users. Further, a case-control design would require varied outcome measures and exceptionally large 
sample sizes to balance the extreme heterogeneity in patient conditions and functional status. Therefore, this research project is descriptive in nature and is an important contribution to the literature, given the scarcity of articles describing chiropractic care in subacute neurorehabilitation inpatient settings.

\section{Chiropractic care pilot project}

This project facilitated and evaluated the integration of chiropractic services at $\mathrm{CMSH}$. The investigative team, composed of CMSH administrative and clinical staff and researchers from the Palmer Center for Chiropractic Research (PCCR), initiated formal activities in January 2015. In March 2015, PCCR researchers introduced the project through a grand rounds presentation. Administrative activities included creating a chiropractic job description, modification of $\mathrm{CMSH}$ medical staff by-laws to support an additional discipline, and the interviewing and hiring process. Chiropractor salary support was funded by the study grant.

In October 2015, CMSH added a chiropractic provider to the professional staff. This licensed Doctor of Chiropractic (DC) had engaged in private practice for more than 20 years prior to and concurrent with joining the $\mathrm{CMSH}$ medical staff. During the first 6 weeks of employment, the DC completed the medical staff and insurance credentialing process and an orientation program, including direct observation of service provision by several disciplines (physical and occupational therapy, primary care, pediatrics, physiatry, and nursing). The DC attended a neurorehabilitation conference ${ }^{34}$ to enhance his knowledge of brain injury research, clinical characteristics, and care challenges of this population. Orientation activities included attending weekly interdisciplinary care planning meetings, developing the chiropractic treatment spaces, and institution-specific training in infection control and patient transfer methods (eg, lifts, slide boards). Following orientation, the DC was available onsite for 2 days (16 hours) per week, with incremental increases in patient assignment until a full case load was established. After $\sim 9$ months, the number of hours per week increased to 20 , still occurring on 2 separate days (Tuesdays/Thursdays).

\section{Data collection and instruments}

Data collection was designed pragmatically to minimize participant burden and influence on usual practices. Chiropractic utilization and patient characteristics were collected using 2 separate methods. Data collection method 1 included with 28 patients (November 2015-December 2016). The DC prospectively recorded de-identified data at each visit using an investigator-designed form. Data included service date, patient age and gender, treatment duration, visit location, clinical diagnoses, care challenges, treatment techniques, and procedures or tests. These 28 patients included some, but not all, of the patients who consented to the method 2 data collection procedure. Method 2 included 27 consented patients who received chiropractic services between January 2016 and January 2017. Electronic health record (EHR) data were retrospectively reviewed. The EHR data included demographics, diagnoses, case management, functional status using the Functional Independence Measure (FIM), and clinical assessments using the Minimum Data Set (MDS).

The FIM ${ }^{\circledR}$ (Uniform Data System for Medical Rehabilitation, Amherst, NY, USA) is a gold standard measure of symptom severity and disability ${ }^{35}$ used in hospital, rehabilitation, and skilled nursing settings. The overall scale and motor and cognitive subscales assess major gradations in function ranging from dependence to independence. Ratings quantify the need for assistance from another person or device. ${ }^{36}$ The FIM is considered a reliable and valid instrument for assessing patients with SCI, stroke, and TBI. ${ }^{37,38}$ FIM measures were obtained by certified CMSH staff at designated intervals appropriate for each patient. For the results presentation, the 8 major gradations were collapsed into 4 categories.

The MDS is a standardized demographic and clinical assessment of health status and care needs mandated for use in residents of Medicare- or Medicaid-certified nursing facilities. ${ }^{39,40}$ The MDS helps providers identify, track, and manage health problems such as physical and psychosocial function, pain, and activities of daily living (ADLs). The MDS also includes a comprehensive list of clinical comorbidities. Designated CMSH staff completed MDS components, including Resident Assessment Protocols (RAPs) for care planning, with the process overseen and entered into the electronic database by a registered nurse who served the facility as an MDS coordinator.

\section{Data management and analysis}

Data collected with method 1 were recorded on paper forms, which were double-key entered into a delimited file. Data collected with method 2 were exported from the electronic health record system MatrixCare (Bloomington, MN, USA) and uploaded to an electronic communications module developed and maintained by the Palmer Center for Chiropractic Research to serve as a secure, 21 Code of Federal Regulations part 11 compliant electronic data transfer system. A research data manager transferred EHR files to a secure file server for data processing, which included de-identification Variables from PDF documents were double-key entered into 
a delimited file. Data obtained from XML sources underwent a schema map process to facilitate data analysis. As patients often had multiple FIM scores and MDS records, the date closest to the initiation of chiropractic care, either before or after enrollment, were selected for data analysis. All data were analyzed descriptively with SAS 9.4 (SAS Institute Inc., Cary, NC, USA).

\section{Results}

\section{Demographics}

MDS data described the mean (SD) age of 27 participants as 42.8 (13) years (range 20-64 years). Male patients $(n=18$, $67 \%)$ and persons of white race/ethnicity $(n=23,85 \%)$ comprised the sample majority. Marital status was reported as never married $(n=12,44 \%)$, married $(n=7,26 \%)$, or divorced $(n=5,19 \%)$. Most admissions were referred from acute care hospitals $(n=21,78 \%)$ or inpatient rehabilitation facilities $(n=4,15 \%)$. The median length of stay for patients discharged during the data collection period $(n=12)$ was 7.5 months. Twelve months was the median length of stay for patients still under care at the end of data collection $(n=15)$. The median length of stay for these 2 groups combined was 10 months. Length of stay ranged from 0 (admitted during the last month of data collection) to 44 months.

\section{Clinical characteristics}

EHR data provided a complex portrait of the primary admitting diagnoses and significant comorbidity (Table 1). Most patients suffered a primary diagnosis indicating brain injury, either from physical trauma $(n=9)$, nontraumatically induced local hemorrhage $(n=7)$, ischemic infarction $(n=2)$, or general anoxia $(n=2)$. Three patients were rehabilitating from complete or incomplete cervical SCI. One patient was admitted for ankylosing spondylitis, 1 for traumatic polyarthropathy, and 2 for respiratory failure with encephalopathy. Common comorbidities (Table 1) that posed significant rehabilitation challenges included myospasm or dystonia; depression, anxiety, and other psychiatric disorders; dysphagia; substance abuse; and candidiasis. Frequent neuromusculoskeletal diagnoses included hemiplegia, shoulder pain, low back pain, and complex regional pain syndrome. Three patients currently used tobacco products.

Table 2 outlines clinical care needs of chiropractic patients as identified by the MDS. The majority ( $85 \%$ ) used a wheelchair as a mobility aid and up to $30 \%$ relied upon at least one, and often multiple medical devices, such as a catheter, feeding tube, or ostomy. The most common RAPs
Table I Primary admitting and significant comorbid diagnoses of participants treated with chiropractic care

\begin{tabular}{|c|c|}
\hline Primary admitting diagnoses & $\begin{array}{l}\text { Total patients } \\
(\mathrm{n}=27)\end{array}$ \\
\hline \multicolumn{2}{|l|}{$\begin{array}{l}\text { Brain injury (subarachnoid, subdural, or } \\
\text { intracerebral hemorrhage) }\end{array}$} \\
\hline Nontraumatic & 7 \\
\hline Traumatic & 3 \\
\hline \multicolumn{2}{|l|}{ Brain injury (nonhemorrhagic) } \\
\hline Local infarction & 2 \\
\hline General anoxia & 2 \\
\hline Trauma (eg, motor vehicle accident, falls) & 6 \\
\hline \multicolumn{2}{|l|}{ Cervical spinal cord injury } \\
\hline Incomplete & I \\
\hline Complete & 2 \\
\hline Ankylosing spondylitis & I \\
\hline Traumatic polyarthropathy & I \\
\hline Respiratory failure with encephalopathy & 2 \\
\hline Significant comorbid diagnoses & $\begin{array}{l}\text { Total patients } \\
(\mathrm{n}=27)\end{array}$ \\
\hline Myospasm, contracture, and dystonia & 15 \\
\hline Depression & 11 \\
\hline Anxiety & 10 \\
\hline Infection (candidiasis, hepatitis) & 9 \\
\hline Dysphagia & 8 \\
\hline Substance abuse & 8 \\
\hline Mood disorders & 7 \\
\hline Pressure/nonpressure ulcer & 6 \\
\hline Hemiplegia/hemiparesis & 6 \\
\hline Shoulder pain & 5 \\
\hline Low back pain & 5 \\
\hline Neurogenic bladder or bowel & 5 \\
\hline Type 2 diabetes mellitus & 5 \\
\hline Cardiac conditions & 4 \\
\hline Chronic respiratory conditions & 4 \\
\hline Encephalopathy or encephalitis & 4 \\
\hline Psychosis & 3 \\
\hline Seizure syndromes & 3 \\
\hline Complex regional pain syndrome & 2 \\
\hline
\end{tabular}

Notes: Admitting diagnoses generated from different regional facilities using overlapping terminology. For example, intracerebral hemorrhage and cerebral infarction can be otherwise described as hemorrhagic and ischemic stroke.

triggered for patients included ADL functional/rehabilitation potential (89\%), urinary incontinence/catheter (89\%), falls $(89 \%)$, pressure ulcer $(81 \%)$, psychotropic drug use $(78 \%)$, and pain (63\%). Pain management needs were considerable, with $85 \%$ of patients reporting pain in the last 5 days, pain that was constant or frequent (63\%), pain described as moderate to very severe $(63 \%)$, and pain impacting sleep (52\%) or daily activities $(30 \%)$. Nonmedication pain interventions were received by $67 \%$ of the sample. A scheduled pain medication regimen was prescribed for $22 \%$.

FIM scores were available for 25 chiropractic patients. Figure 1 graphs FIM scores for key measures of cognition 
Table 2 Clinical care needs of chiropractic patients per Minimum Data Set $(n=27)$

\begin{tabular}{|c|c|c|}
\hline Mobility devices used & $\mathbf{N}$ & $\%$ \\
\hline Wheelchair & 23 & 85 \\
\hline Walker & 7 & 26 \\
\hline Cane/crutches & 3 & II \\
\hline \multicolumn{3}{|l|}{ Medical devices used } \\
\hline External catheter & 8 & 30 \\
\hline Feeding tube & 8 & 30 \\
\hline Tracheostomy & 6 & 22 \\
\hline Intermittent catheterization & 5 & 19 \\
\hline Respiratory suction & 5 & 19 \\
\hline Trunk physical restraints & 4 & 15 \\
\hline Indwelling catheter & 2 & 7 \\
\hline Ostomy & I & 4 \\
\hline \multicolumn{3}{|l|}{ Resident Assessment Protocols triggered } \\
\hline ADL functional/rehabilitation potential & 24 & 89 \\
\hline Urinary incontinence/catheter & 24 & 89 \\
\hline Falls & 24 & 89 \\
\hline Pressure ulcer & 22 & 81 \\
\hline Psychotropic drug use & 21 & 78 \\
\hline Pain & 17 & 63 \\
\hline Cognitive loss/dementia & 12 & 44 \\
\hline Mood state & 10 & 37 \\
\hline Communication & 10 & 37 \\
\hline Behavioral symptoms & 4 & 15 \\
\hline Physical restraints & 4 & 15 \\
\hline \multicolumn{3}{|l|}{ Pain management concerns } \\
\hline Required pain assessment interview & 26 & 96 \\
\hline Reported pain or hurting any time in last 5 days & 23 & 85 \\
\hline $\begin{array}{l}\text { Received or offered/declined as needed pain } \\
\text { medication }\end{array}$ & 22 & 81 \\
\hline Received nonmedication intervention for pain & 18 & 67 \\
\hline $\begin{array}{l}\text { Reported pain or hurting almost constantly or } \\
\text { frequently in last } 5 \text { days }\end{array}$ & 17 & 63 \\
\hline $\begin{array}{l}\text { Reported worst pain intensity in last } 5 \text { days as } \\
\text { moderate, severe, or very severe }\end{array}$ & 17 & 63 \\
\hline Reported pain impacted sleep in last 5 days & 14 & 52 \\
\hline Reported pain limited activities in last 5 days & 8 & 30 \\
\hline Received scheduled pain medication regimen & 6 & 22 \\
\hline
\end{tabular}

Abbreviation: ADL, activity of daily living.

(A) and motor function (B). In the cognitive domain, most patients, on average, required minimal to maximal assistance and were most likely to exhibit difficulties with tasks requiring problem-solving, memory, and comprehension. In the motor function domain, nearly all patients required at least minimal assistance with most activities. Fifty percent or more of patients treated with chiropractic care required moderate, maximal, or total assistance with self-dressing, toileting, walking, and transfer mobility. Walking with or without a wheeled walker was the mobility category with the greatest number of patients exhibiting modified or complete independence $(n=6)$.
A

Functional Independance Measure: cognitive skills

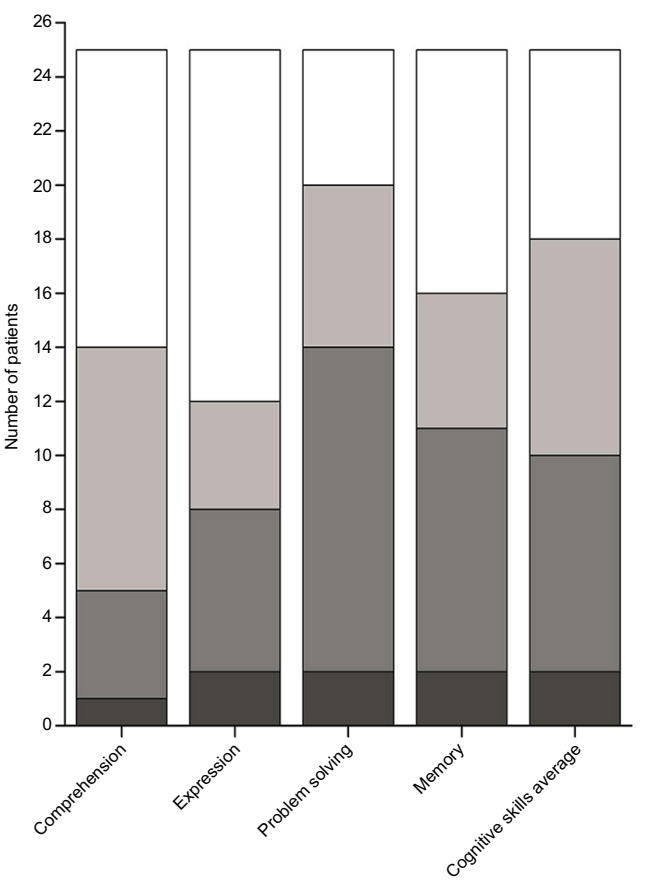

B

Functional Independance Measure: motor skills

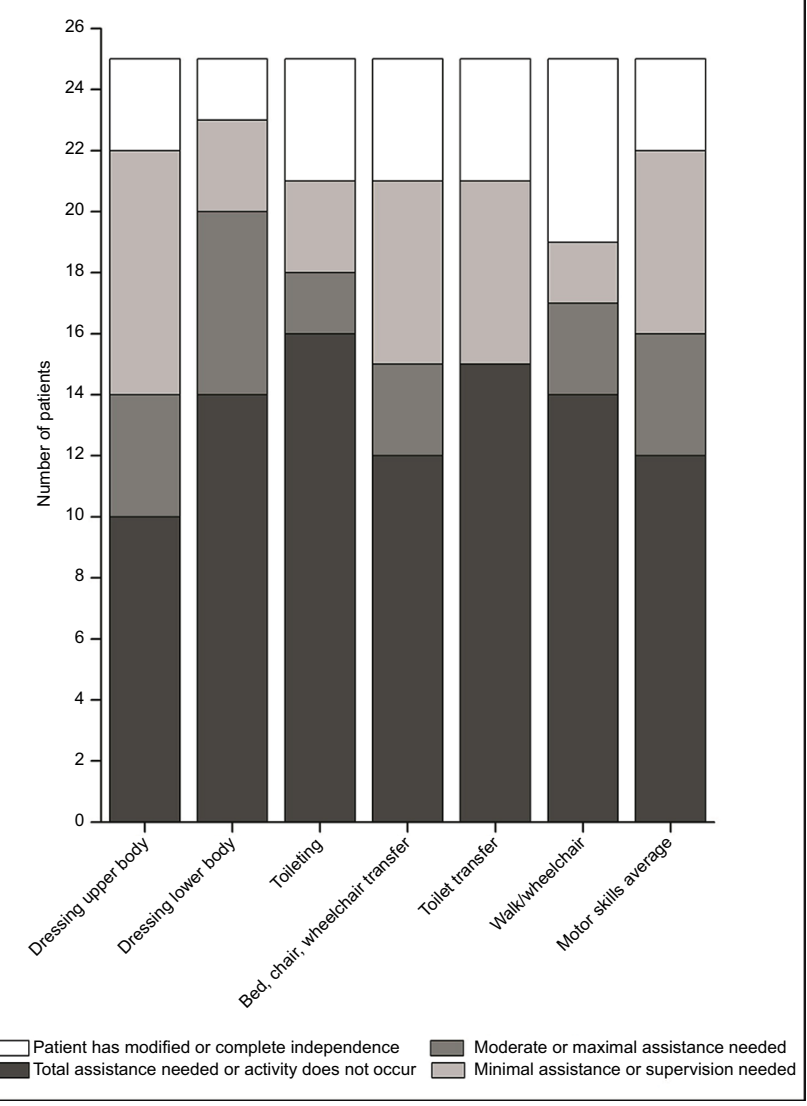

Figure I Functional Independence Measure subscales: cognitive (A) and mobility (B) categories. 


\section{Chiropractic utilization and service delivery}

Daily census ranged around 45 adult inpatients, with most eligible for a chiropractic evaluation. Following orientation, the number of chiropractic visits ranged from 8 to 12 patients daily, depending on case complexity. The DC evaluated or treated 28 new patients in 641 visits over 13 months. Male patients were involved in $68 \%(\mathrm{n}=438)$ of all visits. Individuals rehabilitating from brain injury accounted for $42 \%$ $(n=266)$ of the total chiropractic visits, followed by visits from patients recovering from stroke $(n=153,24 \%)$, SCI $(n=67$, $10 \%)$, and polytrauma $(\mathrm{n}=79,7 \%)$.

Most chiropractic visits $(\mathrm{n}=462,72 \%)$ occurred in 1 of 3 suites that included large, flat, padded therapy tables and transfer equipment such as Hoyer lifts to move patients from wheelchairs. Only $5 \%$ of visits occurred in a designated treatment room due to space constraints that prevented the use of transfer equipment, the limitations of chiropractic equipment for patients with mobility restrictions, and the proximity of patient rooms to therapy suites. Another $21 \%$ of visits occurred within a hospital room, per patient preference. Mean (SD) patient contact time was estimated at 25 (11) minutes. Total chiropractic visit duration was $\sim 45$ minutes, including transport, evaluation, treatment, and documentation. Chiropractic visits were scheduled in the same manner as other disciplines.

\section{Chiropractic case management}

Chiropractic care primarily addressed musculoskeletal symptoms, most commonly spine-related pain $(n=15,54 \%)$, joint or regional stiffness $(\mathrm{n}=14,50 \%)$, and extremity pain $(\mathrm{n}=13$, $46 \%$ ). Less commonly addressed symptoms included general pain management $(n=5,18 \%)$ and mobility restriction $(n=1$, $4 \%$ ). Table 3 displays therapeutic procedures employed. The most common procedures based on the percentage of visits were manual myofascial therapies, such as soft tissue mobilization and ischemic compression (93\%), mechanical percussion (VibraCussor ${ }^{\circ}$; IMPAC Inc., Salem, OR, USA) $(83 \%)$, manual muscle stretching (75\%), and thrust manipulation to the spine or extremity joints $(65 \%)$.

Table 4 displays the patient care challenges that are not typically encountered in chiropractic outpatient settings. Wheelchairs were used during $89 \%$ of the visits. Two-person transfers were common occurrences (40\%), with patient lifts or transfer devices used in $38 \%$ of visits. Patient positioning was complicated by the presence of braces/orthotics (43\%), muscle contractures $(42 \%)$, other deformity of the physical body $(11 \%)$, quadriplegia $(7 \%)$, or paraplegia $(5 \%)$. Medical
Table 3 Therapeutic procedures employed during chiropractic visits

\begin{tabular}{lll}
\hline Procedures & $\begin{array}{l}\text { Number of } \\
\text { visits }(\mathbf{n = 6 4 1 )}\end{array}$ & \% of visits \\
\hline Myofascial therapy & 595 & 93 \\
Mechanical percussion $^{\mathrm{a}}$ & 529 & 83 \\
Manual muscle stretching $^{\text {Thrust manipulation }}$ & 478 & 75 \\
Passive exercise $_{\text {Manipulation (mechanical) }}^{\mathrm{b}}$ & 417 & 65 \\
Sustained passive joint stretching $^{\mathrm{c}}$ & 346 & 54 \\
Active exercise $_{\text {Nonthrust manipulation }}$ & 142 & 49 \\
\hline
\end{tabular}

Notes: anechanical percussion was performed with VibraCussor ${ }^{\circledR}$. ${ }^{\text {bMechanical }}$ manipulation was performed with an Activator instrument (Activator Methods ${ }^{\otimes}$ Int. LTD., Phoenix, AZ, USA), ArthroStim ${ }^{\circledast}$ (IMPAC Inc. Salem, OR, USA), or Impulse $\mathrm{IQ}^{\circledR}$ instrument (Neuromechanical Innovations, Chandler, AZ, USA). 'Sustained stretch of pelvis/low back using padded blocks was performed to orient position with resting bodyweight supplying stretching force.

Table 4 Factors adding to visit complexity for chiropractic care (by visit)

\begin{tabular}{lll}
\hline Care challenge & $\begin{array}{l}\text { Number of } \\
\text { visits (n=64 I) }\end{array}$ & \% of visits \\
\hline Wheelchair & 571 & 89 \\
Braces/orthoses worn by patient & 278 & 43 \\
Contractures present & 270 & 42 \\
Two-person transfer needed & 256 & 40 \\
Hoyer lift or other lift assistance needed & 245 & 38 \\
Impaired speech, limiting communication & 192 & 30 \\
Urinary catheter present & 138 & 22 \\
Feeding tube present & 127 & 20 \\
Deformity & 70 & 11 \\
Quadriplegia & 45 & 7 \\
Coma & 42 & 7 \\
Wounds/infection present & 45 & 7 \\
Gastrointestinal distress & 43 & 7 \\
Paraplegia & 31 & 5 \\
Behavioral challenges & 9 & 1 \\
\hline
\end{tabular}

devices, such as urinary catheters $(22 \%)$ or feeding tubes $(20 \%)$, and patient medical conditions, such as the presence of wounds $(7 \%)$ or gastrointestinal distress $(7 \%)$, often required additional time for infection control procedures. While behavioral challenges among patients were rare $(1 \%$ of visits), impaired speech (30\%) or coma (7\%) limited doctor-patient communication.

\section{Discussion}

Musculoskeletal symptoms are common in individuals suffering from neurological injury. ${ }^{9,10}$ Chiropractic care primarily addressed spine and extremity-related musculoskeletal pain and joint or regional stiffness. Though chiropractic care delivered in outpatient settings similarly focuses on musculoskeletal conditions, it is often delivered in relative 
isolation from other health care interventions. At this facility, chiropractic care differed from typical delivery in several ways. For example, in this setting, patient care goals focused mainly on symptom reduction and functional improvement in the context of moderate to severe preexisting functional limitation and in support of the rehabilitation goals and interventions of the clinical team. Goals to reduce pain held dual purpose, that of relieving suffering, but also of improving ability and willingness to participate in self-care and other rehabilitation activities, often managed by physical or occupational therapists.

The fact that many patients experienced notable and often profound functional limitations created other clinical challenges not typically encountered in most chiropractic settings. The functional limitations experienced by many patients required the chiropractic provider to assist with body movement and positioning, adapt treatment to limited patient mobility or frailty, engage novel communication methods to ensure an appropriate evaluation and understanding of the patient, and recognize that memory and problem-solving ability is compromised in some patients. For some patients, the chiropractic treatment table was too narrow to accommodate physical mobility limitations. Using large flat therapy tables was necessary to accommodate some of these challenges. The presence of feeding tubes, urinary catheters, deformities, paralysis, and contractures requiring treatment accommodation were also common as where needs for patient transfer assistance. In some cases, the general goal of improving mobility of a joint (ankle or wrist) was avoided when patients used such spasticity or stiffness to stabilize a limb during gait or to hold objects such as silverware. In these cases, limb spasticity or limited motion due to contracture or hypertonia was used by patients to support needed functions, requiring the DC to be aware of how otherwise reasonable treatment goals potentially conflict with other rehabilitation strategies.

Most studies describing functional capacity using the FIM report numerical data. In this study, we described functional cognitive and mobility levels as measured with the FIM instrument from a categorical perspective that more intuitively describes functional status. We also combined categories to simplify presentation and understanding of these limitations.

\section{Limitations}

Data for this study were collected through retrospective review of electronic health records using instruments designed for other purposes and prospectively on paper forms generated by the chiropractic provider. Some records did not contain entries for all characteristics reported in this study. The complex picture of patient conditions, care challenges, care provided, and functional status were recorded using different instruments as they occurred in the pragmatic setting. Future studies should explore clinical and safety outcomes from chiropractic care delivered to this patient population.

This study does not address the relative contribution of chiropractic care for patients at this facility, perceived benefit, or the ideal number of visits required. A small sample size and lack of homogenous case controls prevented such a design. However, the addition of chiropractic to the majority of care teams during the study time frame suggests that both other providers and patients perceived an added therapeutic benefit. Finally, chiropractic services were funded by the study grant. Therefore, some aspects of care delivered may not generalize to other settings requiring sustainable fee-for-service or daily rate reimbursement models.

\section{Conclusion}

Most patients in this study suffered from musculoskeletal symptoms such as spine-related pain, muscle or joint stiffness, and extremity dysfunction. This project reported chiropractic services delivered as part of collaboratively developed care plans among interdisciplinary teams focused on rehabilitation for individuals suffering from complex neurological conditions and often with significant comorbidity. Working in this neurorehabilitation context commonly required modifying the approach to patient care to address patients' functional limitations. Such modifications included working closely within interdisciplinary teams, engaging in longer visits, using nonstandard treatment surfaces, improving patient transfer skills, recognizing and adapting to patients with cognitive impairments, and overcoming communication barriers.

\section{Acknowledgments}

This study was funded through the Kiernan Chiropractic Care in Rehabilitation at Crotched Mountain program, a philanthropic gift from Dr William J Kiernan and Mary A Kiernan through the Kiernan Family Trust. The authors also wish to acknowledge Jeb Thurmond, DC, who provided chiropractic care and collected treatment data; Kimberlee Case, BSN, who organized and collected MDS and FIM data; and David Kontak, Master of Arts, Master of Science, Occupational Therapist, Registered, Licensed, who managed recruitment and the informed consent process. 


\section{Author contributions}

CMG, WCC, and RDV participated in funding acquisition. RDV, WCC, SAS, and CMG developed the study design. WCC, DG, LC, and RDV implemented the study. RDV, SAS, and LC performed data analysis and drafted the manuscript. All authors contributed toward data analysis, drafting and critically revising the paper and agree to be accountable for all aspects of the work. All authors provided critical feedback and approved the manuscript.

\section{Disclosure}

The authors report no conflicts of interest in this work.

\section{References}

1. Nas K, Yazmalar L, Sah V, Aydin A, Ones K. Rehabilitation of spinal cord injuries. World J Orthop. 2015;6:8-16.

2. Winstein CJ, Stein J, Arena R, et al. Guidelines for adult stroke rehabilitation and recovery: a guideline for healthcare professionals from the American Heart Association/American Stroke Association. Stroke. 2016;47:e98-e169.

3. Hemphill JC III, Greenberg SM, Anderson CS, et al. Guidelines for the management of spontaneous intracerebral hemorrhage: a guideline for healthcare professionals from the American Heart Association/ American Stroke Association. Stroke. 2015;46:2032-2060.

4. Jain NB, Ayers GD, Peterson EN, et al. Traumatic spinal cord injury in the United States, 1993-2012. JAMA. 2015;313:2236-2243.

5. Benjamin EJ, Blaha MJ, Chiuve SE, et al. Heart disease and stroke statistics - 2017 update: a report from the American Heart Association. Circulation. 2017;135:e146-e603.

6. Centers for Disease Control and Prevention. Report to congress on traumatic brain injury in the United States: epidemiology and rehabilitation. Atlanta: Division of Unintentional Injury Prevention; 2015.

7. Ma VY, Chan L, Carruthers KJ. Incidence, prevalence, costs, and impact on disability of common conditions requiring rehabilitation in the United States: stroke, spinal cord injury, traumatic brain injury, multiple sclerosis, osteoarthritis, rheumatoid arthritis, limb loss, and back pain. Arch Phys Med Rehabil. 2014;95:986-995.

8. Eum RS, Seel RT, Goldstein R, et al. Predicting institutionalization after traumatic brain injury inpatient rehabilitation. $J$ Neurotrauma. 2015;32:280-286.

9. Lew HL, Lombard LA, Reddy CC, Moroz A, Edgley SR, Chae J. Stroke and neurodegenerative disorders: 3. Poststroke rehabilitation. $P M R$. 2009;1:S19-S26.

10. Lombard LA, Reddy CC, Moroz A, Lew HL, Chae J, Edgley SR. Stroke and neurodegenerative disorders: 2 . Poststroke medical complications. PM R. 2009;1:S13-S18.

11. Finnerup NB, Faaborg P, Krogh K, Jensen TS. Abdominal pain in longterm spinal cord injury. Spinal Cord. 2008;46:198-203.

12. Kalichman L, Ratmansky M. Underlying pathology and associated factors of hemiplegic shoulder pain. Am J Phys Med Rehabil. 2011;90: 768-780.

13. Cardenas DD, Felix ER. Pain after spinal cord injury: a review of classification, treatment approaches, and treatment assessment. $P M R$. 2009;1:1077-1090.

14. Finnerup NB, Baastrup C. Spinal cord injury pain: mechanisms and management. Curr Pain Headache Rep. 2012;16:207-216.

15. Gironda RJ, Clark ME, Ruff RL, et al. Traumatic brain injury, polytrauma, and pain: challenges and treatment strategies for the polytrauma rehabilitation. Rehabil Psychol. 2009;54:247-258.
16. Young JA. Pain and traumatic brain injury. Phys Med Rehabil Clin N Am. 2007;18:145-163, vii-viii.

17. Coronado RA, Gay CW, Bialosky JE, Carnaby GD, Bishop MD, George SZ. Changes in pain sensitivity following spinal manipulation: a systematic review and meta-analysis. J Electromyogr Kinesiol. 2012;22:752-767.

18. Bialosky JE, Bishop MD, Price DD, Robinson ME, George SZ. The mechanisms of manual therapy in the treatment of musculoskeletal pain: a comprehensive model. Man Ther. 2009;14:531-538.

19. Arienti C, Dacco S, Piccolo I, Redaelli T. Osteopathic manipulative treatment is effective on pain control associated to spinal cord injury. Spinal Cord. 2011;49:515-519.

20. Lisi AJ, Brandt CA. Trends in the use and characteristics of chiropractic services in the Department of Veterans Affairs. J Manipulative Physiol Ther. 2016;39:381-386.

21. Vining R, Mathers S. Chiropractic medicine for the treatment of pain in the rehabilitation patient. In: Carayannopoulos A, editor. Comprehensive Pain Management in the Rehabilitation Patient. Cham: Springer International Publishing Switzerland; 2017:575-596.

22. Dunn AS, Green BN, Gilford S. An analysis of the integration of chiropractic services within the United States military and veterans' health care systems. J Manipulative Physiol Ther. 2009;32:749-757.

23. Nabhan DC, Moreau WJ, Barylski C. Laboratory tests ordered by a chiropractic sports physician on elite athletes over a 1-year period. J Chiropr Med. 2015;14:68-76.

24. Karlen EK. Implementation of evidence-informed physical therapy and chiropractic care improves value for patients. SpineLine. 2015 Feb. North American Spine Society. Date: January-February 2015. Section: Current Concepts. Available from: http://www.spineline-digital.org/ spineline/january_february_2015?pg=17\#pg17.

25. Vining RD, Gosselin DM, Thurmond J, Case K, Bruch FR. Interdisciplinary rehabilitation for a patient with incomplete cervical spinal cord injury and multimorbidity: a case report. Medicine (Baltimore). 2017;96:e7837.

26. Dagenais S, Brady O, Haldeman S, Manga P. A systematic review comparing the costs of chiropractic care to other interventions for spine pain in the United States. BMC Health Serv Res. 2015;15:474.

27. Menke JM. Principles in integrative chiropractic. J Manipulative Physiol Ther. 2003;26:254-272.

28. Nelson CD, McMillin DL, Richards DG, Mein EA, Redwood D. Manual healing diversity and other challenges to chiropractic integration. J Manipulative Physiol Ther. 2000;23:202-207.

29. Meeker WC. Public demand and the integration of complementary and alternative medicine in the US health care system. J Manipulative Physiol Ther. 2000;23:123-126.

30. Bowden BS, Ball L. Nurse practitioner and physician assistant students' knowledge, attitudes, and perspectives of chiropractic. JChiropr Educ. 2016;30:114-120

31. Wong JJ, Di LL, Kara A, et al. Assessing the change in attitudes, knowledge, and perspectives of medical students towards chiropractic after an educational intervention. J Chiropr Educ. 2014;28: 112-122.

32. Dellefield ME. Interdisciplinary care planning and the written care plan in nursing homes: a critical review. Gerontologist. 2006;46: 128-133.

33. Commission on the Accreditation of Rehabilitation Facilities (CARF). 2018 Medical Rehabilitation Program Descriptions. 2018:2-11.

34. 36th Annual Neurorehabilitation Conference, 11 July, 1985; Cambridge, MA.

35. Corrigan JD, Smith-Knapp K, Granger CV. Validity of the functional independence measure for persons with traumatic brain injury. Arch Phys Med Rehabil. 1997;78:828-834.

36. Hall KM, Cohen ME, Wright J, Call M, Werner P. Characteristics of the Functional Independence Measure in traumatic spinal cord injury. Arch Phys Med Rehabil. 1999;80:1471-1476. 
37. Hsieh YW, Wu CY, Lin KC, Chang YF, Chen CL, Liu JS. Responsiveness and validity of three outcome measures of motor function after stroke rehabilitation. Stroke. 2009;40:1386-1391.

38. Beninato M, Gill-Body KM, Salles S, Stark PC, Black-Schaffer RM, Stein J. Determination of the minimal clinically important difference in the FIM instrument in patients with stroke. Arch Phys Med Rehabil. 2006;87:32-39.
39. Long Term Care Minimum Data Set (MDS). Available from: www. CMS.gov. Accessed August 24, 2015.

40. Mor V. A comprehensive clinical assessment tool to inform policy and practice: applications of the minimum data set. Med Care. 2004;42:III50-III59.
Journal of Multidisciplinary Healthcare

\section{Publish your work in this journal}

The Journal of Multidisciplinary Healthcare is an international, peerreviewed open-access journal that aims to represent and publish research in healthcare areas delivered by practitioners of different disciplines. This includes studies and reviews conducted by multidisciplinary teams as well as research which evaluates the results or conduct of such teams or health

\section{Dovepress}

care processes in general. The journal covers a very wide range of areas and welcomes submissions from practitioners at all levels, from all over the world. The manuscript management system is completely online and includes a very quick and fair peer-review system. Visit http://www.dovepress.com/ testimonials.php to read real quotes from published authors.

Submit your manuscript here: https://www.dovepress.com/journal-of-multidisciplinary-healthcare-journal 